\title{
Graphitization behavior of iodine-treated Bombyx mori silk
}

\section{fibroin fiber}

\author{
Md. Majibur Rahman $\operatorname{Khan}^{2}$, Yasuo Gotoh ${ }^{1 *}$, Hideaki Morikawa ${ }^{1}$, and Mikihiko Miura ${ }^{1}$ \\ ${ }^{1}$ Faculty of Textile Science and Technology, Shinshu University, Tokida 3-15-1, Ueda,
}

Nagano 386-8567, Japan

${ }^{2}$ Department of Biosystems Engineering, University of Manitoba, Winnipeg MB, R3T

5V6, Canada

*Corresponding author. Tel: +81-268-21-5366, Fax: +81-268-21-5370.

E-mail address: ygotohy@shinshu-u.ac.jp ; majib@hotmail.com.

\begin{abstract}
In order to investigate the graphitization behavior of Bombyx mori silk fibroin (SF) fibers, structural inspection of carbonized SF fibers treated with iodine vapor was studied at different temperatures, from 800 to $1400{ }^{\circ} \mathrm{C}$. Wide angle X-ray diffraction measurement suggested that both untreated and iodinated SF fiber exhibited amorphous structure carbonized to $1200{ }^{\circ} \mathrm{C}$. After carbonized at $1400{ }^{\circ} \mathrm{C}$ for $12 \mathrm{~h}$, a graphite-like structure was obtained. Raman spectroscopy and transmission electron microscopic observation showed that the graphite layers of SF fibers became more ordered after iodine treatment. The carbon yield obtained at higher temperature $\left(1400{ }^{\circ} \mathrm{C}\right)$ after iodine treatment was higher, ca. $28 \mathrm{wt} \%$, than that of untreated SF.
\end{abstract}

Keywords: silk fibroin; graphitization; X-ray diffraction; Transmission electron microscopy; microstructure; carbon yield.

\section{Introduction}

Silk-based carbon is an attractive raw material for the applications in bio- and electrochemical fields, such as, wound dressing, hydrogen storing materials, hazardous substance decomposer, electric double layer capacitor, electrode of fuel cells, electro conductive ink and electro conductive paste for higher electro conductivity performance 
and thermal conductive paste, thermal conductive sheet and various heat dissipation composite materials [1-7].

Recent researches have been revealed that iodine is a good stabilizing agent for producing higher yield carbon materials [8-12]. Kajiura et al. prepared the pitches by the direct reaction with iodine at a temperature near the softening point of the parent pitch and then carbonized them at $1073 \mathrm{~K}$ [8]. The iodine treatment was effective at increasing the carbon yield and it also changed optical microstructure of the carbonized substance from flow type of isotropic. Miyajima et al. obtained an extremely high carbon yield, over $90 \mathrm{wt} \%$, of iodine treated coal tar pitch and explained the dehydrogenative polymerization as a charge transfer complex caused by iodine treatment during carbonization of pitches $[9,10]$. Furthermore, iodine treatment process has also been performed on other polymeric precursors, such as, polyacrylonitrile [11], poly(vinyl alcohol) [12], in order to produce high performance and high functional carbon materials and resultantly some interesting features accompanied by high carbon yield were found.

Many researchers reported on the carbonization process silk fibroin (SF) fibers [13-17]. The carbonization at $800{ }^{\circ} \mathrm{C}$ of silk fibers was investigated and non-graphitizing carbon obtained with a carbon yield of $30 \%$ [13]. A novel nitrogen-rich carbon material, silk carbon, was prepared from SF by simple heat-treatment under inert atmosphere and the activation of the silk carbons with steam and potassium hydroxide provided nitrogen-containing activated carbons (ACs) with different pore-size distribution [14]. In the application to electric double layer capacitors, the silk carbon-based ACs showed a higher capacitance and an excellent electrochemical stability in the high voltage region, compared with a typical AC prepared from phenolic resin.

Recently, the authors have shown that iodine is an excellent stabilizing agent for producing higher yield silk-based carbon materials $[15,16]$. We produced carbon fibers from SF fibers treated with iodine vapor at $100{ }^{\circ} \mathrm{C}$ for $12 \mathrm{~h}$ and then carbonization was carried out by heating to $800{ }^{\circ} \mathrm{C}$ in Ar atmosphere at a multi-step carbonization process (at a nearly constant decomposition rate of silk in order to inhibit the rapidly thermal decomposition). Both strength and the carbon yield (yield $36 \mathrm{wt} \%$ in case of Bombyx mori SF, and $39 \mathrm{wt} \%$ in case of Antheraea pernyi SF) of the carbon fibers obtained were considerably increased after iodine treatment. The structures of the carbon fibers obtained at $800{ }^{\circ} \mathrm{C}$ from both untreated and iodinated SF were almost the same and amorphous. However, until recently, graphitization behavior of SF has not been studied yet.

The graphite fiber is a high strength material used for many sophisticated material applications. In the beginning of graphite fiber production, regenerated cellulose fiber (rayon) was used as a starting raw material $[18,19]$. Heretofore, it was replaced by polyacrylonitrile fibres owing to its specials advantages, like high yield, and stretchability during pyrolysis that leads to higher crystallinity and orientation. The possibility of using SF for graphite fiber production attracts our attention for its higher yield after carbonization with iodine treatment in compare with cellulose fibers and as well as for higher order crystalline structure of silk. In this study we examined the graphitization behavior of iodinated SF fiber at a temperature between 800 to $1400{ }^{\circ} \mathrm{C}$ and elucidated the crystalline structure using Raman spectroscope, wide angle X-ray diffraction (WAXD), transmission electron microscopy (TEM) and elemental analysis. 


\section{Experimental}

\section{Materials}

The dominant Bombyx mori (B. mori) SF was used in the experiment. In order to remove sericin from the raw silk, the degumming process was achieved by the standard Marseille soap/soda ash method [20]. This process removed almost all the sericin. The degummed SF fiber was soft and smooth with a fine sheen.

\section{Iodine treatment}

The iodine treatment of SF fiber was carried out as follows: an adequate quantity of SF fiber was enclosed with abundant iodine in a small test tube in a glass vessel. After sealing the glass vessel, it was placed in an oven heated at $100{ }^{\circ} \mathrm{C}$ where iodine was vaporized and kept for several periods. The color of SF fiber turned to dark brown by the treatment. The iodine sorption content was calculated by measuring the weight change of the SF fibers before and after the iodine treatment.

We used SF fibers treated with iodine vapor at $100^{\circ} \mathrm{C}$ for $12 \mathrm{~h}$ for experiments.

\section{Graphitization}

SF fibers were heated to different temperatures, $800,1000,1200$, and $1400{ }^{\circ} \mathrm{C}$ in a tubular furnace under an Ar flow under a multi step carbonization process, which was defined based on the optimum thermal degradation rate of silk. The fibers were maintained at that temperature of $1400{ }^{\circ} \mathrm{C}$ for $12 \mathrm{~h}$ to observe the grahitization behavior of SF fibers. The detail heating conditions were described in our previous report [15]. In brief, to determine the heating condition of SF fiber, dynamic thermogravimetric analysis (dynamic TGA) was performed using constant reaction control (CRC) mode at $-0.001 \mathrm{wt} \% / \mathrm{sec}$ of constant weight reduction rate from room temperature to $800{ }^{\circ} \mathrm{C}$ with a Rigaku Thermo plus II TG 8120 under an Ar atmosphere. According to the dynamic TG result, we defined a multi steps heating schedule for carbonization and the untreated and iodinated specimens were heated from 25 to $800{ }^{\circ} \mathrm{C}$ in a tubular furnace under an Ar gas flow using the multi step heating condition. Then samples were graphitized to $1400{ }^{\circ} \mathrm{C}$ for $12 \mathrm{~h}$.

\section{Sample preparation}

We used 10 individual lots of degummed SF fibers for the experiments. Each lot was divided into two sub portions. In each lot, one portion was observed as original specimen and another portion was treated with iodine vapor at $100{ }^{\circ} \mathrm{C}$ for $12 \mathrm{~h}$. Finally, untreated and iodinated specimens of 10 individual lots were graphitized at desired temperatures and used for different experiments.

\section{Measurements}

The weight loss percentages of untreated and iodinated SF were determined by 
measuring the weight change of the SF fibers before and after carbonization at different temperatures.

Raman spectroscopy was measured by S. T. Japan, Inc. HoloLab-5000, equipped with a MK-II filtered probe head using Nd: YAG (Yttrium Aluminum Garnet) laser beam of $532 \mathrm{~nm}$ generated at $50 \mathrm{~mW}$. The measurement was carried out under the conditions of resolution of $2.5 \mathrm{~cm}^{-1}$ with $10 \mathrm{~s}$ exposure 10 times.

Wide angle X-ray diffraction (WAXD) profile was obtained by a Rigaku Rotorflex RU-200B diffractometer using Ni-filtered $\mathrm{CuK}_{\alpha}$ radiation generated at $40 \mathrm{kV}$ and 150 $\mathrm{mA}$.

Transmission electron microscopic (TEM) observation was conducted at an acceleration voltage of $200 \mathrm{kV}$ using JEOL JEM-2010 instrument.

The elemental analysis was performed on a Parkin-Elmer 2400 II analyzer using the normal procedure.

\section{Results and discussion}

Figure 1 shows XRD patterns of iodinated SF carbonized at different temperature from 800 to $1400{ }^{\circ} \mathrm{C}$. From the results, it was observed that at $800{ }^{\circ} \mathrm{C}$, one broad peak was exhibited at $2 \theta=24.3^{\circ}$ for both untreated and iodinated SF, which indicates an amorphous structure. This peak remained through carbonized to $1200{ }^{\circ} \mathrm{C}$. When the specimen were carbonized at $1400{ }^{\circ} \mathrm{C}$ for $12 \mathrm{~h}$, peaks at $2 \theta=26.0^{\circ}$ (lattice spacing, $\mathrm{d}=$ $3.42 \AA$ ) was developed, which corresponds to the scattering from the (002) face of graphite [21]. There fore, a graphite-like structure for the carbonized SF obtained at the heating temperature of $1400{ }^{\circ} \mathrm{C}$ is likely. In case of iodinated SF, the (002) peak is more visible, which suggests that iodine treatment has influenced SF molecules to build a graphite like structure.

Raman spectroscopy has been utilized to study the deformation micromechanics of a large number of polymetric incompletely crystallized materials with cracks, internal stress etc [22,23]. Generally, carbons show mainly two Raman bands, one is at ca. $1580 \mathrm{~cm}^{-1}$ and another is at ca. $1360 \mathrm{~cm}^{-1}$. The former corresponds to the $E_{2 \mathrm{~g}}$ mode of graphite, known as graphite peak ( $\mathrm{G}$ band) and is assigned to the "in-plane" displacement of the carbons strongly coupled in the hexagonal sheets. The latter, which is absent in the single crystal graphite, known as disorder peak ( $\mathrm{D}$ band) due to discontinuity of hexagonal carbon layer planes such as finite crystallite size and also to edge planes of crystallites [22]. Consequently, a linear relation was found between the ratio of areas of the $\mathrm{D}$ and $\mathrm{G}$ band $\left(I_{\mathrm{D}} / I_{\mathrm{G}}\right)[24,25]$. In addition to the $I_{\mathrm{D}} / I_{\mathrm{G}}$ ratio, other graphitization parameters such as the peak position and the full-width at half-maximum of $\mathrm{G}$ band $\left(P_{\mathrm{G}}\right.$ and $\left.\mathrm{FWHM}_{\mathrm{G}}\right)$ and the width of the $\mathrm{D}$ band $\left(\mathrm{FWHM}_{\mathrm{D}}\right)$ were proposed $[26,27]$. The width of the two bands decreased with increasing graphite order and the $P_{\mathrm{G}}$ is shifted from higher wavenumbers to the position of graphite. Figure 2 shows the Raman spectra of carbon fibers prepared from untreated and iodinated SF at $1400{ }^{\circ} \mathrm{C}$ for $12 \mathrm{~h}$. Observed results are plotted with gray closed circles. Black broken and solid lines represent the deconvoluted and total curves, respectively, which were fitted by Gaussian function. Table 1 represents the peak position, the FWHM and the intensity ratio of the two peaks, $I_{\mathrm{D}} / I_{\mathrm{G}}$ obtained from the Gaussian fittings. The spectra of untreated SF were shown two peaks at $1350 \mathrm{~cm}^{-1}$ for $\mathrm{D}$ band and at $1587 \mathrm{~cm}^{-1}$ for $\mathrm{G}$ band. The peaks are 
broad and are similar to a pattern of diamond-like carbon which posses low crystallinity and mixture of $\mathrm{sp}^{2}$ and $\mathrm{sp}^{3}$ carbons. After iodine treatment, the intensity ratio of $I_{\mathrm{D}} / I_{\mathrm{G}}$ and the two bands widths are decreased. Furthermore, $P_{\mathrm{G}}$ is shifted from 1587 to 1580

$\mathrm{cm}^{-1}$, which is an indication that the graphite like layers in the SF fibers became more ordered after iodine treatment.

Figure 3 shows the TEM images of carbon fibers prepared from untreated and iodinated SF at $1400{ }^{\circ} \mathrm{C}$ for $12 \mathrm{~h}$. Both the carbon fibers exhibited layered structure with disordering contained in some part. Especially, in case of iodinated SF, it has been shown carbon layers with an average thickness of $0.38 \mathrm{~nm}$ as similar as expected from the XRD pattern developed over a scope as wide as tens of nanometers in size.

Figure 4 shows the results of elemental analysis for the carbon fibers prepared at $1400{ }^{\circ} \mathrm{C}$ for $12 \mathrm{~h}$. For untreated specimen, the $\mathrm{C}, \mathrm{H}, \mathrm{N}$, and $\mathrm{O}$ contents were ca. 90, 6, 0.3 and $3 \mathrm{~mol} \%$, respectively. After iodine treatment, the elemental compositions were raised at ca. 93, 5, 0.3 and $2 \mathrm{~mol} \%$, respectively. The results indicated that carbon contents were increased and the ratio of carbon to oxygen was maximized after iodine treatment.

Figure 5 shows the carbon yield of untreated and iodinated SF fibers at different temperatures. The weight residue percentages of untreated SF carbonized at 800, 1000, 1200 and $1400{ }^{\circ} \mathrm{C}$ were ca. 29, 28, 24 and $23 \mathrm{wt} \%$, respectively. After iodine treatment, the carbon yields considerably increased and reached up to ca. 36, 31, 29 and $28 \mathrm{wt} \%$, at $800,1000,1200$ and $1400{ }^{\circ} \mathrm{C}$, respectively. It was conformed that iodine could not be detected in the specimen after carbonized at different temperatures. Considering these results, iodine treatment seems an effective process to increase carbon yield of SF fibers at higher temperature.

\section{Conclusions}

The effects of iodine treatment on the carbonization and graphitization characteristics of $B$. mori SF fibers were studied. Prior to heating, SF fibers were treated with iodine vapor at $100{ }^{\circ} \mathrm{C}$ for $12 \mathrm{~h}$. Untreated and iodinated SF fibers were carbonized to different temperatures, $800,1000,1200$, and $1400{ }^{\circ} \mathrm{C}$ in a tubular furnace under an Ar flow under a multi step carbonization process, which was defined based on the optimum thermal degradation rate of silk. WAXD measurement suggested that both untreated and iodinated SF fiber showed amorphous structure carbonized to $1200{ }^{\circ} \mathrm{C}$. After carbonized at $1400{ }^{\circ} \mathrm{C}$ for $12 \mathrm{~h}$, a graphite-like structure was obtained. In case of iodinated SF, the (002) peak was more visible, which suggests that iodine treatment has been influenced SF molecules to build a graphite like structure. Raman spectroscopy and TEM observation showed that the graphite like layers in the SF fibers became more ordered after iodine treatment. The carbon yield obtained at higher temperature $\left(1400{ }^{\circ} \mathrm{C}\right)$ after iodine treatment was higher, ca. $28 \mathrm{wt} \%$, than that of untreated SF. ( $c f$. ca. $23 \mathrm{wt} \%$ of carbon yield for untreated SF).

\section{Acknowledgements}

This work was supported by The Global COE Program and Grant-in-Aid for Scientific Research program by the Ministry of Education, Science, Sports and Culture of Japan. The authors gratefully thank to Professor Fujio Okino, Dr. Yoshiyuki Hattori 
and Mr. Hisatoshi Koshikawa, Faculty of Textile Science and Technology, Shinshu University, Japan for their help of TEM measurements.

\section{References}

1. Hashizume H, Shimizu M, Yawata T, Kimura M (2005) Patent application (in Japanese), PCT Int. Appl. WO 2005007287

2. Hashizume H, Shimizu M, Yahata T (2005) Patent application (in Japanese), Jpn. Kokai Tokkyo Koho JP 2005081307

3. Hashizume H, Shimizu M, Yahata T, Endo M (2005) Patent application (in Japanese), Jpn. Kokai Tokkyo Koho JP 2005112667

4. Hashizume H, Shimizu M, Yawata T (2005) Patent application (in Japanese), PCT Int. Appl. WO 2005008815

5. Miyashita M, Iwasaki T, Shimizu M (2006) Patent application (in Japanese), Jpn. Kokai Tokkyo Koho JP 2006100798

6. Yoshioka M (2002) Patent application (in Japanese), Jpn. Kokai Tokkyo Koho JP 2002363572

7. Hayashi S (2002) Patent application (in Japanese), Jpn. Kokai Tokkyo Koho JP 2002220745

8. $\quad$ Kajiura H, Tanabe Y, Yasuda E (1997) Carbon 35 (2): 169

9. Miyajima N, Dohi S, Akatsu T, Yamamoto T, Yasuda E, Tanabe Y (2002) Carbon 40: 1533

10. Miyajima N, Yasuda E, Rand B, Akatsu T, Kameshima K, Tanabe Y (2000) Tanso 195: 405

11. Ito T, Sadanobu J (2002) Patent application (in Japanese), Jpn. Kokai Tokkyo Koho JP 2002155428

12. Mukuruma S, Oki H, Shiotani M, Yamashita J (2004) Patent application (in Japanese), Jpn. Kokai Tokkyo Koho JP 2004339627

13. Nishikawa G, Kawahara Y, Shioya M, Kimura T (2004) Sen'I Gakkaishi 60(4): 105

14. Kim YJ, Abe Y, Yanagiura T, Park KC, Shimizu M, Iwazaki T, Nakagawa S, Endo M (2007) Carbon 45(10): 2116

15. Khan MMR, Gotoh Y, Miura M, Morikawa H, Fujimori Y, Nagura M (2007) Carbon 45: 1035

16. Khan MMR, Gotoh Y, Miura M, Morikawa H (2008) J Appl Polym Sci 110 (3): 1358

17. Rusakov NG, Petrov E (1938) Shelk 8(6): 26

18. Tang MM, Bacon R (1964) Carbon 2: 211

19. Bacon R, Silvaggi AF (1971) Carbon 9: 321

20. Kato H (1968) In: Silk Processing Techniques and Its Application, Elsevier, Amsterdam, Chapter 1, pp. 18

21. Seeley SB (1978) In: Encyclopedia of Chemical Technology, Kirk-Othmer, 3rd ed., Wiley, New York, 4: 689

22. Shiraishi M (1996) In: New introduction to carbon materials, Tokyo, Realize, pp. 24

23. Eichhorn SJ, Hughes M, Snell R, Motto L (2000) J Mater Sci Lett 19: 721

24. Tuinstra F, Koenig Jack L (1970) J Chem Phys 53: 1126 
25. Knight DS, White WB (1989) J Mater Res 4: 385

26. Lespade P. Marchand A (1984) Carbon 22: 375

27. Johnson CA, Thomas KM (1984) Fuel 63: 1073

\section{List of Tables and Figures}

Fig. 1. Equatorial WAXD profiles of carbon fibers prepared from untreated and iodinated SF carbonized at $1400{ }^{\circ} \mathrm{C}$ for $12 \mathrm{~h}$ : (a) untreated specimen, (b) iodinated specimen.

Fig. 2. Raman spectra of carbon fibers prepared from untreated and iodinated SF carbonized at $1400{ }^{\circ} \mathrm{C}$ for $12 \mathrm{~h}$ : (a) untreated specimen, (b) iodinated specimen.

Fig. 3. TEM images of carbon fibers prepared from untreated and iodinated SF carbonized at $1400{ }^{\circ} \mathrm{C}$ for $12 \mathrm{~h}$ : (a) untreated specimen, (b) iodinated specimen.

Fig. 4. Elemental composition of carbon fibers prepared from untreated and iodinated SF carbonized at $1400{ }^{\circ} \mathrm{C}$ for $12 \mathrm{~h}$ : (a) untreated specimen, (b) iodinated specimen.

Fig. 5. Carbon yield of untreated and iodinated SF fibers obtained at different heating temperature: $(\circ)$ untreated specimen, $(\bullet)$ iodinated specimen.

Table 1. Structural parameters of carbon fibers prepared from untreated and iodinated SF carbonized at $1400^{\circ} \mathrm{C}$ for $12 \mathrm{~h}$ determined by Raman spectroscopy. 


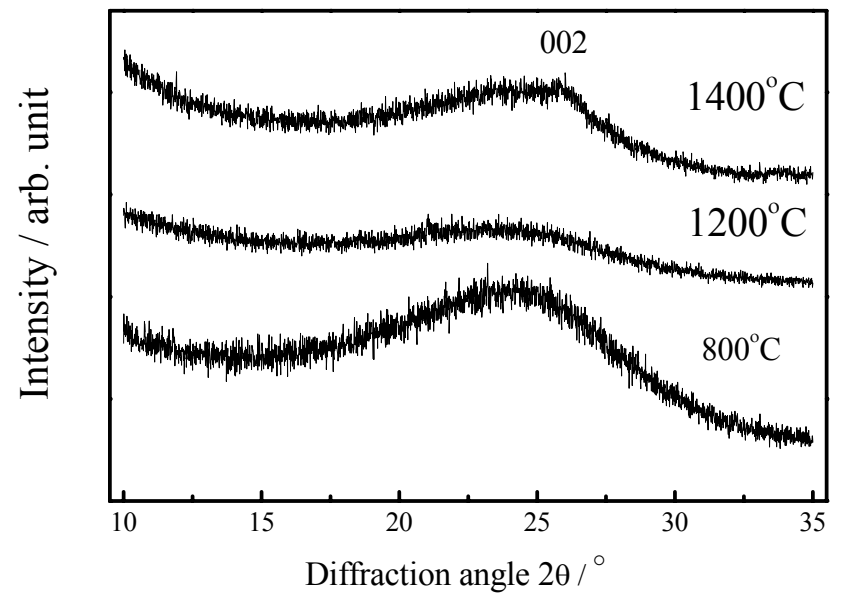

(a)

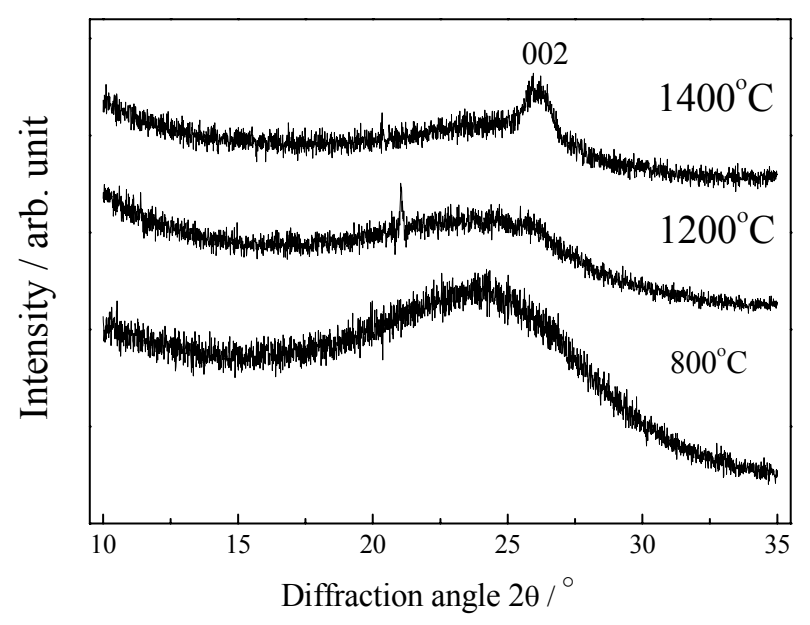

(b)

Fig. 1. Equatorial WAXD profiles of carbon fibers prepared from untreated and iodinated SF carbonized at $1400{ }^{\circ} \mathrm{C}$ for $12 \mathrm{~h}$ : (a) untreated specimen, (b) iodinated specimen. 


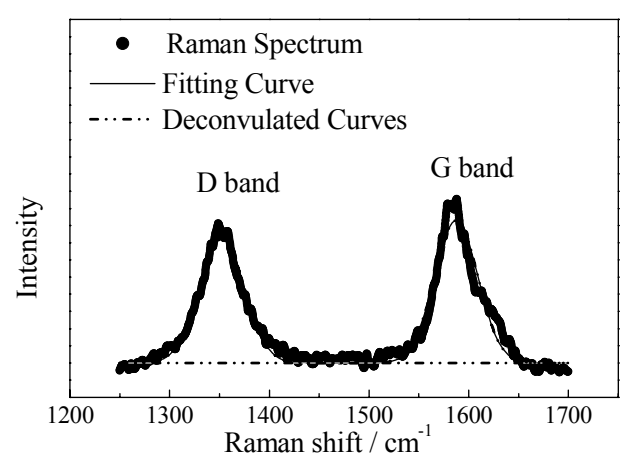

(a)

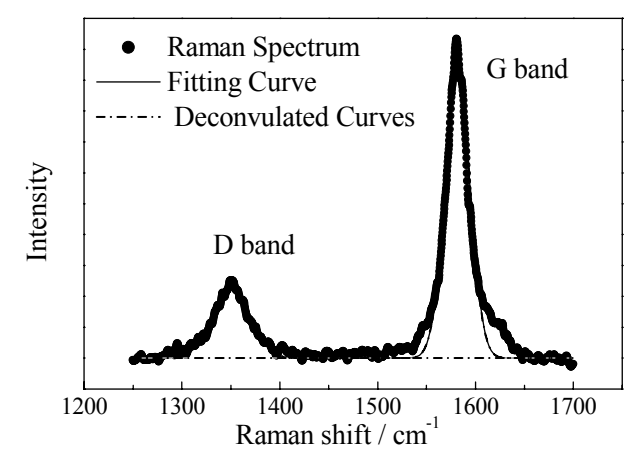

(b)

Fig. 2. Raman spectra of carbon fibers prepared from untreated and iodinated SF carbonized at $1400{ }^{\circ} \mathrm{C}$ for $12 \mathrm{~h}$ : (a) untreated specimen, (b) iodinated specimen. 
(a)

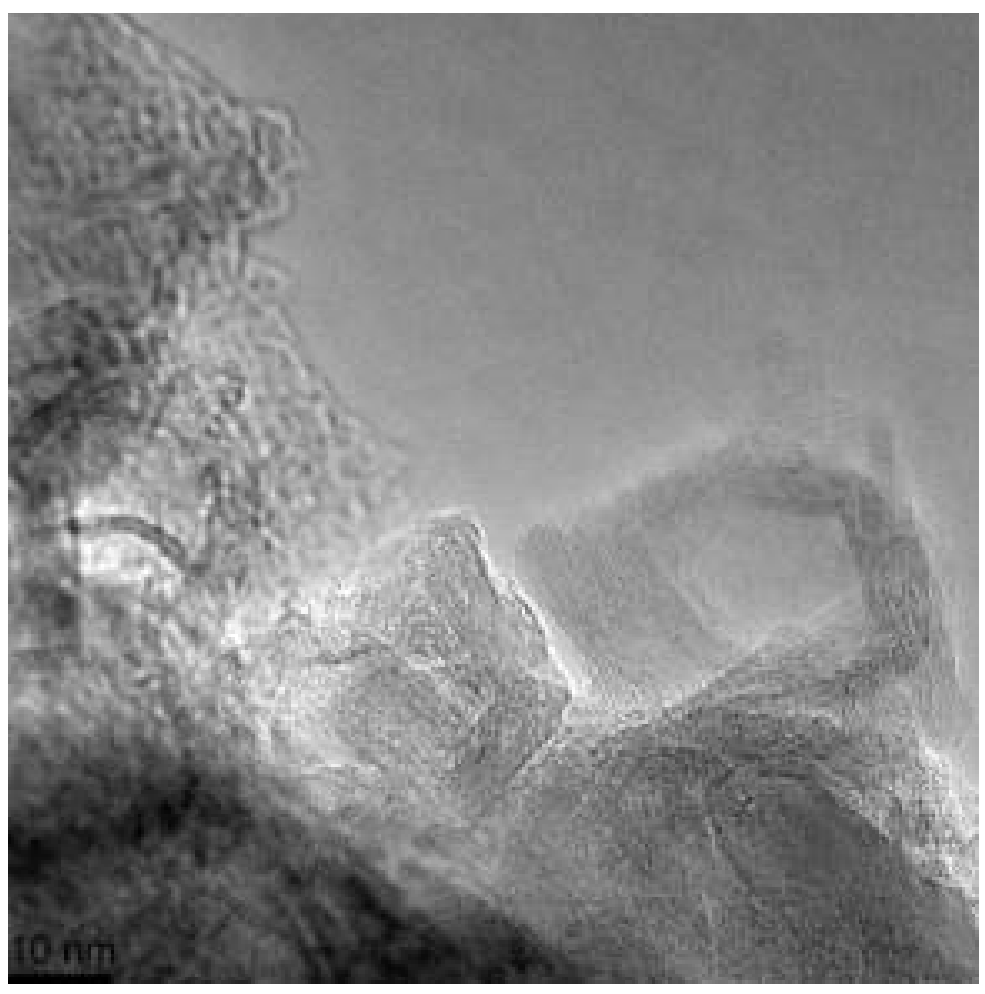

(b)

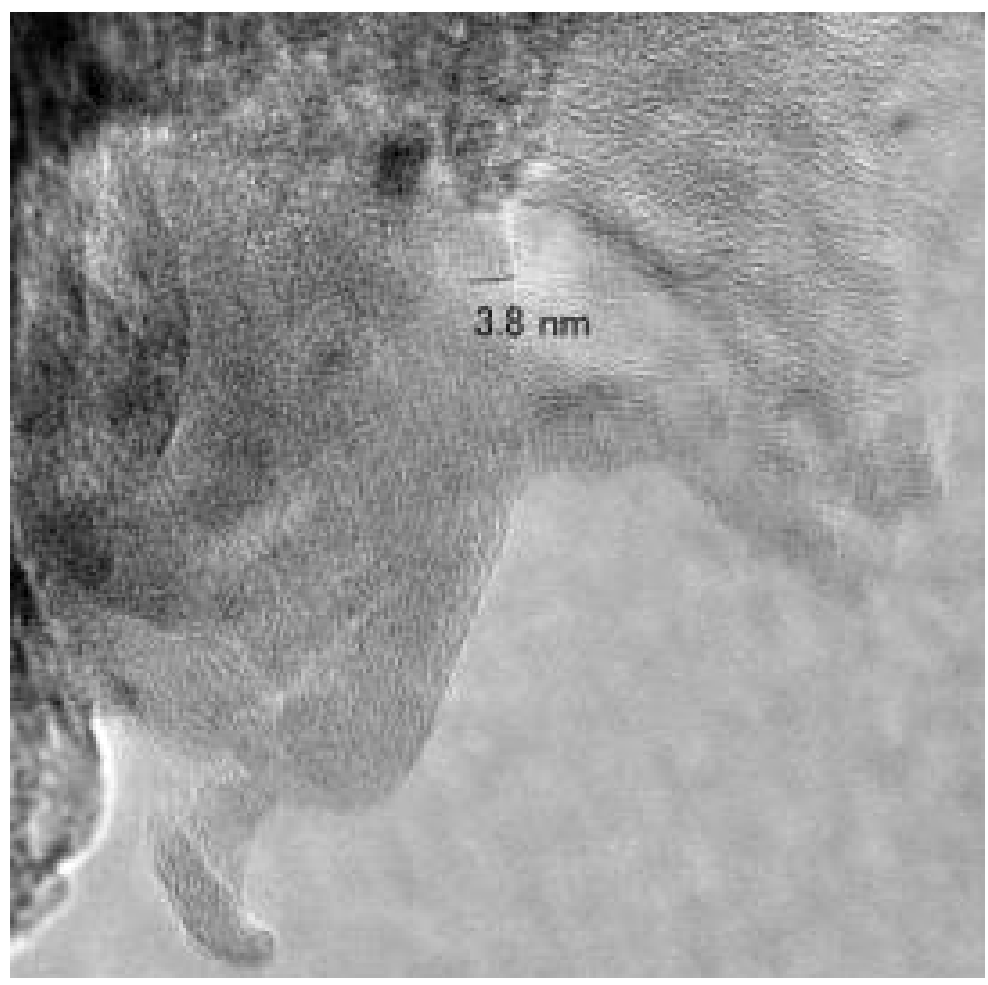

Fig. 3. TEM images of carbon fibers prepared from untreated and iodinated SF carbonized at $1400{ }^{\circ} \mathrm{C}$ for $12 \mathrm{~h}$ : (a) untreated specimen, (b) iodinated specimen. 


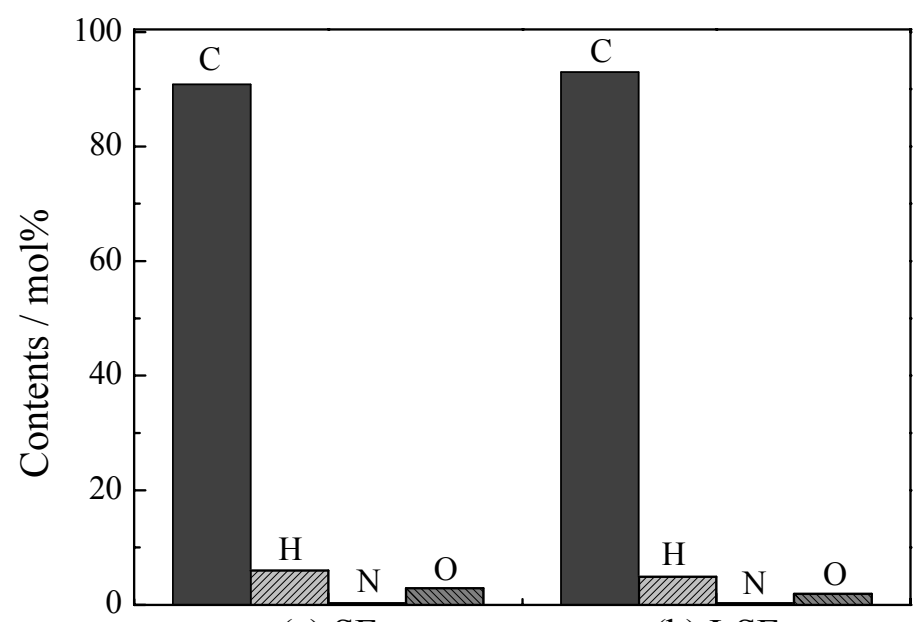

$\begin{array}{ll}\text { (a) } \mathrm{SF} & \text { (b) I-SF }\end{array}$

Fig. 4. Elemental composition of carbon fibers prepared from untreated and iodinated SF carbonized at $1400{ }^{\circ} \mathrm{C}$ for $12 \mathrm{~h}$ : (a) untreated specimen, (b) iodinated specimen.

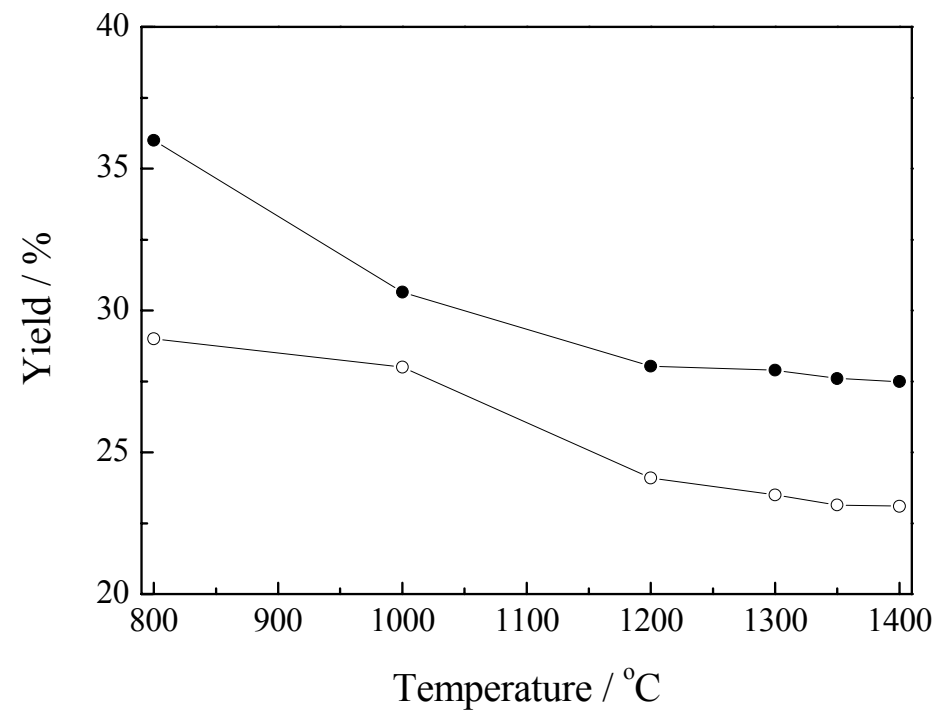

Fig. 5. Carbon yield of untreated and iodinated SF fibers obtained at different heating temperature: $(\circ)$ untreated specimen, $(\bullet)$ iodinated specimen. 
Table 1. Structural parameters of carbon fibers prepared from untreated and iodinated $\mathrm{SF}$ carbonized at $1400^{\circ} \mathrm{C}$ for $12 \mathrm{~h}$ determined by Raman spectroscopy

\begin{tabular}{|c|c|c|c|c|c|}
\hline \multirow{2}{*}{ Specimen } & \multicolumn{2}{|c|}{ G band } & \multicolumn{2}{c|}{ D band } & \multirow{2}{*}{$\mathrm{I}_{\mathrm{D}} / \mathrm{I}_{\mathrm{G}}$} \\
\cline { 2 - 5 } & $\begin{array}{c}\text { Peak Position } \\
\left(\mathrm{cm}^{-1}\right)\end{array}$ & $\begin{array}{c}\text { FWHM } \\
\left(\mathrm{cm}^{-1}\right)\end{array}$ & $\begin{array}{c}\text { Peak Position } \\
\left(\mathrm{cm}^{-1}\right)\end{array}$ & $\begin{array}{c}\text { FWHM } \\
\left(\mathrm{cm}^{-1}\right)\end{array}$ & \\
\hline Untreated SF & 1587 & 51 & 1350 & 53 & 0.89 \\
\hline Iodinated SF & 1581 & 30 & 1350 & 45 & 0.29 \\
\hline
\end{tabular}

